\title{
Revisit Exports-Growth Nexus in Turkey
}

\begin{abstract}
Alper Yilmaz ${ }^{\mathrm{a}}$
Abstract: The aim of this paper is to investigate exports and economic growth causality in Turkish economies. In this sense, we employed seasonally adjusted quarterly data of economic growth (real GDP) rate and exports that cover 1987Q1-2018Q4 periods. We analyze the relationship between variables by taking into account standard bootstrap Granger non-causality test and fixed-size rolling-window estimation approach. Standard Granger causality test indicates one direction causality that running from exports to real GDP. But according to test of parameters constancy, conducted VAR model points to parameters instability both in the short and long-run periods. Parameters constancy test indicate that empirical results are not uniform for different sample periods and vary due to structural changes. Consideringly, under parameters inconstancy, results of rolling window estimation method indicate that there is positive two way Granger causality (predictive power) between variables from the early 1990s to end of 2018 periods.
\end{abstract}

Keywords: Export-led Growth (ELG), Output-driven Export, Time-Varying Causality

JEL: F43, 010, Q48

$\begin{array}{ll}\text { Received } & : 19 \text { September } 2019 \\ \text { Revised } & : 07 \text { November } 2019 \\ \text { Accepted } & : 21 \text { November } 2019 \\ \text { Type } & : \text { Research }\end{array}$

\section{Introduction}

A few topics in economics have been subject to heated debate in the case of export and growth linkage. Because there is disagreement among scholars about whether exports or economic growth are promote or neutral with to each other. Although numerous papers have been studied, empirical results remain ambiguous and the case is not clear. So it's hard to generalize this relationship across different economies or different time period. At first glance one could easily suppose an expanding in exports gives rise to more economic growth over the multiplier effect in an open economic model. On the other hand, increases in GDP could also give rise to realization of economies of scale and cost reduction that could in turn lead to increase in exports (Oskooee \& Economidou, 2009).

In this context there are four numbers of theoretical frameworks that refer to possible relationship between these variables. First one is "Export Led Growth" (ELG) hypothesis. ELG hypothesis connects with foreign trade and development and argue that there is a positive relationship which goes from export to economic growth due to basic formulation (expenditure approach) of GDP. This model proposes that the growth of a country is closely related to its export performance. If we look at this model closely, exports have positive sign. This strategy involves that any nation which has a comparative advantage can promotes its economic growth by exporting more goods and services. (Hultman, 1967). Foreign trade strategy that based on comparative advantage results with higher export volume and in turn this means better growth performance. But this strategy implies opening domestic markets to foreign competition valorously in exchange for market access in partner countries. Removing trade barriers, decreasing custom duties, technological advances in exportable sectors, exposing firms to foreign competition, reducing production 
cost, increasing productivity, floating exchange rate and public support and incentives for exporting sectors are main elements of this strategy (Yang \& Wu, 2008).

In this frame any countries which have an aspiration to follow sustainable growth path can find a chance to penetrate foreign markets and in turn utilize their economy from economies of scale. Secondly increase in exports ease foreign exchange constraints by paving the way for increase in imports and also inflow of foreign currency. Third, increases in exports serves as efficient allocation of resource and capacity use in domestic economy due to fierce competition in the world markets. Fourth increase in export volume enable for more imports of intermediate goods that require for manufacturing through providing foreign exchange which in turn raises capital formation, higher employment, increasing level of high technology knowledge and raising profits in domestic economy. This stage further increases in investment and in turn boosts economic growth. Last, raise in exports is helpful in the case of accelerating spread of know-how via interactions with the foreign firms. Sum up this relationship between export and economic growth implies unidirectional granger causality run from export to economic growth. (Balcılar \& Özdemir, 2013).

But ELG strategy has some risks. First, it disrupts the function of domestic market as it force infant domestic industries to compete with strong foreign rivals. Second, it forces developing countries into destructive competition with each other. Third, workers in developed countries may be conflict with workers in developing countries and in turn this may means low salary for them in the long run. Fourth, ELG strategy may lead to over investment that is one of the reasons for financial instability. Fifth, ELG model may lead to distortion in terms of trade for developing countries due to due to over emphasis on global goods and commodity markets. Finally, ELG worsen the dependency of developing countries to developed economies, thus becoming fragile to downturn in the latter's markets. Export-oriented economies are highly dependent on foreign demand naturally. So global recession like 2008 financial downturn affects many export-oriented economies negatively (Balassa, 1978; Krueger, 1980; Grossman \& Helpman, 1991; Felipe, 2003).

Feedback (bidirectional) hypothesis is the third perspective that requires a two way causal relationship. It has resulted from mutual dependence between these two variables. This interdependence alleged a policy that when there is negative effect on one of these variables, it would also affect the other variables negatively. In other words, economic recession can be negatively transmitted back to export performance or decrease in export volume restricts economic growth. (Helpman \& Krugman, 1985).

The last approach is the neutrality hypothesis. This view handles the subject in the context of ineffectiveness. This hypothesis proposes any causality in either way between variables. More clearly, exports and economic growth may be determined by other variables such as foreign direct investment, interest rates, employment, expectations in the economic system. For this reason, increases in exports may not affect economic growth or vice versa (Pack, 1988; Özer \& Erdoğan, 2006).

\section{Literature Review}

There is an extensive body of theoretical and empirical study on the causal relationship between growth and exports for both developed and developing economies. The outcomes of individual studies vary according to selected econometric method, time period, variables or data process. In this manner, the findings range from uni-directional to bi-directional causality. Also, some studies find no causality relationship between these variables.

Among these papers there are many researchers aim to answer the same question for Turkish economy. First group has resulted within favour of the ELG hypothesis. Özcan and Özçelebi (2013) employed Johansen co-integration method for Turkish economy over the period 2005Q1-2015Q1 and the results are in support of export-led growth hypothesis. Korkmaz (2014) tries to search the same subject by using quarterly data of 1998Q1-2013Q3 with Granger test and found that unidirectional causality has seen from exports to economic growth. Sağlam and Egeli (2015) check the validity of ELG hypothesis for 1999Q1-2013Q4 by using co-integration tests and Granger causality test and results support the hypothesis that there is bi-directional causality in the short run and unidirectional causality between variables in the long run. Bilgin and Şahbaz (2009) investigate the same relationship for Turkey by using 1987-2007 monthly data with Johansen co- 
integration method and granger test and their results support ELG hypothesis for the specified period. İzgi and Yılmaz investigate the relationship between exports, imports and growth variables by using Johansen cointegration analyses over 1992-2016 periods and authors revealed that there was one cointegration vector between variables and also they found evidence in support of ELG hypothesis.

On the other hand there are some studies against ELG hypothesis. Temiz and Gökmen (2010) examine the real net export and economic growth link by using yearly data for the Turkish economy over the period 1950-2006. The results show that there is unidirectional causality run from economic growth to real net exports. Aktaş (2009) examines export-growth relationship using yearly data for 1996-2009 periods with Johansen cointegration and granger non-causality test and results indicate uni-directional causality relationship that goes from economic growth to export. Taştan (2010) uses frequency domain methods for the 1985.01-2009.05 period and find that granger-causality runs from imports to industrial production index. These findings support "import-led growth" and "growth-driven exports" hypotheses.

Thirdly some studies indicate that there is bidirectional causality between variables. Küçükaksoy et al. (2015) employed Toda-Yamamoto causality test for the period from 2003Q1 to 2015Q1 and the results are proposed two way granger causality. These findings support the ELG and GLE hypothesis for Turkey. According to FMOLS, CCR, DOLS cointegration parameters estimation methods, $1 \%$ increase in the real export increases the real GDP by $1.5195 \%, 1.5552 \%, 1.3171 \%$ respectively in the long-run. Ay and Gerçeker (2013) analysed export-economic growth relationship for 1998 Q1 to 2010Q4 by using Unit Root Test, VAR Model, Co-Integration Test and Vector Error Correction Model respectively. The evidences suggest a bidirectional and strong causal relationship between variables in contrast to imports-economic growth link when the short term and long term causal results were assessed together. Erdoğan (2006) also find two way relationships between variables for 1923-2004 periods by using cointegration analysis and granger non-causality tests.

Lastly there are also some studies which find no relationship in accordance with neutrality hypothesis. Yıldırım (2015) used both symmetric and asymmetric causality tests that cover the period of 1997:1-2013:4. Findings prove that exports did not raise the industrial ELG hypothesis in long-term is not supported in this study. Takım (2010) uses yearly data from 1975 to 2008 periods and conclude that export growth does not support the economic growth with Granger non causality analysis. Saatçioğlu and Karaca (2004) examine the relationship by yearly data for the periods 1950-1980 and 1981-2000 with Granger non causality test. According to results on the one hand causality relationship is not seen from exports to growth in 1950-1980 periods but ELG hypothesis is supported for the 1981-2000 periods.

As can be seen from specified papers, the conclusions are mixed. But differently from previous analyses, this study examine exports and growth linkage by employing "bootstrap rolling window" approach. All previous article employed granger causality test based on full sample data by using VAR models. But under the parameters inconstancy the results might be illusive due to disregarding of uniform causality that holds in whole time period advise a permanent causal relationship. However our study takes structural change into consideration by using rolling window estimation method. Under structural changes there may be instability across different sub-samples because of dynamic relationship between variables (Balcılar et al., 2010; Balcılar \& Özdemir, 2013).

Sub samples are important because it allows researcher to observe the evolution of causality between different sub-periods and to catch structural changes in the VAR model. Secondly stationarity, integration-cointegration properties and parameter constancy are important for regulatory conditions of granger causality test based on VAR models and our results are robust to the violation of these regularity conditions. Thirdly unlike previous papers, we estimate effect of variables on each other in a time varying manner to exhibit negative or positive effect by using bootstrap estimation. In this sense we conducted analysis traditionally over full sample data than we consider structural changes and so to capture causal relationship between the export and real GDP we utilized from time-varying (128-quarter rolling window) causality tests over the period of 1987Q1 to 2018Q4. 


\section{Data and Methodology}

This empirical study focused on export and economic growth relationship for Turkish economy. In our empirical analysis we use export (EX) and real GDP (RGDP) data. They are expressed in terms of billions of US dollars. All variables are seasonally adjusted to remove seasonal component and made logarithmic transformation to smooth time series (remove outlier) and to stabilize their variance. The sources of the data are World Bank data base and Turkish Statistical Institute.

\subsection{Unit Root and Cointegration Test}

Our analyses start with unit root test. Time series estimations are based on stationary of series. Series are said to be stationary if its mean do not depend on time. But most of economic and financial data exhibit trending behaviour (show nonstationarity) in their mean. In this case regressors invalidate many standard hypothesis tests and spurious results may obtain. This is called the problem of fake regression. This in turn will make a set of series seem as if it has a relation with another set of series. Also, variance of series increases with time. Thus to avoid this drawbacks all series must be stationary (Zivot \& Wang; 2006; Başarır \& Erçakar, 2016). From the followed AR(1) process, two different cases come across;

$$
y_{t}=a+\alpha y_{t-1}+\varepsilon
$$

Where ' $a$ ' is an optional exogenous regressor consist of constant and trend, ' $\alpha$ ' is a parameter has to be estimated and ' $\varepsilon_{\mathrm{t}}$ ' is white noise term. If $|\alpha| \geq 1, \mathrm{y}_{\mathrm{t}}$ is a non-stationary series and If $|\alpha|<1, \mathrm{y}$ is a stationary series (Özkaplan, 2011).

The next step in analyse is cointegration. This test suggests whether the series are not being stable at the level. If there is a co-integration relationship between variables, it means they move together in the long run. In general, if a linear combination of the integrated series is stationary, a set of variables are cointegrated, i.e., if $Y, \sim I(d)$ and $X, \sim I(d)$. The following regression is run; $Y_{t}=6 X_{t}+u_{t}$, if residual $u_{t}$, are $I(0)$, then $X_{t}$, and $Y_{t}$, are said to be cointegrated (Engle \& Yoo, 1986; Engle \& Granger, 1987). It points out comovement of series in the long run. We can follow Johansen's co-integration procedure and start by writing the $p$-dimensional VAR model in its error correction term:

$$
\Delta z_{t}=\sum_{i=1}^{k-1} \Gamma_{i} \Delta z_{t-i}+\alpha \beta^{\prime} z_{t-1}+\mu+\psi D_{t}+\varepsilon_{t}
$$

Where ' $\Delta$ ' is the first difference operator, ' $z_{t}{ }^{\prime}$ is a $p \times 1$ vector of stochastic variables, ' $\alpha$ ' and ' $B$ ' are full rank ' $p \times r^{\prime}$ matrices, ' $\mu$ ' is a constant vector, ' $D_{t}$ ' is a vector of deterministic variables such as linear time trends, seasonal dummies etc. and ' $\varepsilon_{t}$ ' is a normal vector, iid errors with zero means and constant variances. Set $k=2$, and $D_{t}=t$ and rewrite equation 2 as;

$$
\Delta z_{t}=\Gamma_{1} \Delta z_{t-1}+\alpha \beta^{\prime} z_{t-1}+\mu+\delta t+\varepsilon_{t}
$$

Where ' $\mathrm{t}$ ' is a linear time trend. According to Hansen and Juselius (1998) methodology, we decompose ' $\delta$ ' and ' $\mu$ ' into $\delta=\alpha \delta_{1}+\alpha_{0} \delta_{2}$ and $\mu=\alpha \mu_{1}+\alpha_{0} \mu_{2}$, where $\delta_{1}$ is $r$-dimensional vector of linear trend coefficient. $\delta_{2}$ is a ' $p$-r' dimensional vector of quadratic trend coefficients. $\mu_{1}$ is a r-dimensional vector of intercept and $\mu_{2}$ is a ' $p-r$ ' dimensional vector of linear trend slope coefficient. Substituting $\delta$ and $\mu$ into equation 3 , we obtain;

$$
\Delta z_{t}=\Gamma_{1} \Delta z_{t-1}+\alpha\left(\begin{array}{l}
\beta \\
\mu_{1} \\
\delta_{1}
\end{array}\right)^{\prime} \bar{z}_{t-1}+\alpha_{0} \mu_{2}+\alpha_{0} \delta_{2} t+\varepsilon_{t}
$$


In which $\bar{z}_{t-1}=\left(\bar{z}_{t-1}^{\prime}, 1, \mathrm{t}\right)$ are two test statistics. Depending on the restrictions on $\delta_{1}, \delta_{2}, \mu_{1}$, and $\mu_{2}$. The deterministic components can be write in five different ways as case 1 to 5 ;

Table 1. Restrictions on the Deterministic Components

\begin{tabular}{|l|l|}
\hline Cases & \multicolumn{1}{|c|}{ Restrictions } \\
\hline Case 1 & $\delta_{1}=\delta_{2}=\mu_{1}=\mu_{2}=0$ \\
\hline Case 2 & $\delta_{1}=\delta_{2}=\mu_{2}=0, \mu_{1} \neq 0$ \\
\hline Case 3 & $\delta_{1}=\delta_{2}=0, \mu_{1} \neq 0, \mu_{2} \neq 0$ \\
\hline Case 4 & $\delta_{2}=0, \delta_{1} \neq 0, \mu_{1} \neq 0, \mu_{2} \neq 0$ \\
\hline Case 5 & $\delta_{1} \neq 0, \delta_{2} \neq 0, \mu_{1} \neq 0, \mu_{2} \neq 0$ \\
\hline
\end{tabular}

Among them case 1 and case 5 are rather unusual. But other cases may contain cointegration relationship. In equation (5) the rank of $\Gamma_{1}$ matrix determines the number independent rows in $\Gamma_{1}$ and also the number of co-integrating vectors. If rank $r=k$ and $r=0$ there is no cointegration relationship but if rank $r<k-1$ there is ' $r$ ' number of cointegration relationship (Dolado et al, 1999: 12). Johansen proposes two different likelihood ratio tests of the significance of these canonical correlations and thereby the reduced rank of the $\Pi$ matrix: the trace test and maximum eigenvalue test are shown in the following equation;

$$
J_{\text {trace }}=-T \sum_{i=r+1}^{n} \ln \left(1-\hat{\lambda}_{i}\right) \quad \text { and } \quad J_{\max }=-T \ln \left(1-\hat{\lambda}_{r+1}\right)
$$

' $T$ ' is the sample size and $\hat{\lambda}_{i}$ is the $i$ th. largest canonical correlation. Null hypothesis of $r$ cointegrating vectors is tested against the alternative of $n$ cointegrating vectors by trace value. On the other hand maximum eigenvalue tests the null hypothesis of $r$ cointegrating vectors against the alternative of $r+1$ cointegrating vectors (Hjalmarson \& Österhölm, 2007).

\subsection{Full Sample Granger Causality Test}

In standard granger test, because of zero limitations for parameters, test statistic is obtained from Wald approach and applied chi-square distribution. On the other hand if VAR model contains non stationary variables, $\mathrm{F}$ and chi-square distribution may have non-standard asymptotic properities. In their analyses Sims, Stock, and Watson (1990), Toda and Phillips (1993) indicated that if the process is I(1), Wald test statistic for Granger noncausality not only has a nonstandard asymptotic distribution but also depends on nuisance parameters. Secondly in the case of cointegration, Park and Phillips (1989) and Sims, Stock, and Watson (1990) have proved that the standard asymptotic theory is not applicable to hypothesis testing. A researcher would determine an ECM model If their variables are $1(1 ; 1)$. However in finite samples of Johansen-type $E C M$ 's, simulation experiments indicated that values of the nuisance parameters are very sensitive and hence not very robust to sample sizes. To overcome these problems, Toda and Yamamoto (1995) and Dolado and Lutkepohl (1996) developed a test that is applicable to VAR models even in the stationary, integrated or cointegrated cases. Due to these methods, regardless to the integration and cointegration properties of the time series any researcher can test restrictions on the coefficients by estimating a VAR model in levels and applying the Wald criterion. Also researcher guarantees standard asymptotic distribution for the Wald tests that performed on the coefficients of VAR(p) processes with I(1) variables. This is called Modified Wald Test

(MWald) and has an asymptotic chi-square distribution with $\mathrm{m}$ degrees of freedom $\left(\chi_{m}^{2}\right)$. But according to this solution one coefficient matrix should be unrestricted under the $\mathrm{H}_{0}$ hypothesis. Additionally, Toda and Yamamoto (1995) indicate that standard asymptotic distribution can be obtained by adding one extra lag to the process and performing the MWald tests on the coefficient matrices relating to first $p$ lags (Hacker \& Hatemi-J, 2006). 
However Shukur and Mantalos (1997a) have analysed the size and power properties of Modified Wald test and they concluded that it did not result in correct size in small or even medium-sized samples (size distortion). To overcome this problem they showed that the critical values must be improved by using the residual-based bootstrap (RB) technique. When the assumptions of the test do not hold bootstrap method offers an alternative method to asymptotic approach so this technique produces robust critical values. (Shukur \& Mantalos, 1997b). Bootstrap estimation method uses critical values or $p$-values which are obtained from the empirical distribution (Efron, 1979). In our case, bootstrap is used to test for Granger non-causality. Consider VAR ( $p$ ) model in matrix form including a constant term can be written compactly as;

$$
Y=B Z+\delta
$$

We can estimate this model by using the OLS method. From regression (6), a direct residual resampling gives;

$$
Y^{*}=B^{*} Z^{*}+\delta^{*}
$$

Where $\delta^{*}$ are i.i.d observations $\left(\delta_{1}^{*}, \ldots \ldots, \delta_{\mathrm{T}}^{*}\right)$ that drawn from the empirical distributions $\left(\hat{F}_{\delta}\right)$. It puts mass $1 / \mathrm{T}$ to the adjusted OLS residuals $\hat{\delta}_{i}-\bar{\delta}, \mathrm{i}=1,2 \ldots . \mathrm{T}$. Drawing a number of bootstrap samples from the model under the null hypothesis and correspondingly calculating the bootstrap test statistic $\left(T_{S}^{*}\right.$; can be calculated by repeating this step about $\mathrm{N}_{\mathrm{b}}$ number of times) are basic principles of this method. After calculating test statistic $T_{S}^{*}$ based on actual data set, we than take the ' $\alpha$ ' th. quintile of the bootstrap distribution and we obtain the ' $\alpha$-level' bootstrap critical values $c_{t \alpha}^{*}$. Finally we can reject the null hypothesis if $\mathrm{T}_{\mathrm{s}}>c_{t \alpha}^{*}$ (Salman \& Shukur, 2004).

After calculating test statistic, we should check the robustness of the estimation. At this point, Horowitz (1994), Mantalos and Shukur (1998) have been shown several studies about the robustness of the estimation by using Monte Carlo methods. They compared the properties of Wald, corrected-LR and bootstrap tests in cointegrated and non-cointegrated processes and they proved that bootstrap test exhibits the best performance regardless of integration-cointegration properties. So this paper uses RB based on corrected-LR tests to analyse causality relationship between export and real GDP. In order to apply bootstrap modified LR Granger causality, we should follow bivariate VAR ( $p)$ model;

$$
Z_{t}=\Phi_{0}+\Phi_{1} Z_{t-1}+\Phi_{2} Z_{t-2}+\ldots \ldots \ldots+\Phi_{p} Z_{t-p}+\varepsilon_{t}, \quad t=1,2, \ldots . T
$$

Where $\varepsilon_{\mathrm{t}}=\left(\varepsilon_{1, \mathrm{t}} ; \varepsilon_{2, \mathrm{t}}\right)$ is a zero mean independent white noise with non-singular covariance matrix $\Sigma$. $p$ is lag order of the process and it is determined by using the Akaike Information Criterion (AIC). VAR (p) process $Z_{t}$ can be divided into two subsector to simplify the representation. First part is related with export $\left(Z_{\mathrm{mt}}\right)$ and second part is GDP $\left(Z_{\mathrm{yt}}\right)$. This equation can be re-rewrite as;

$$
\left[\begin{array}{c}
Z_{m t} \\
Z_{y t}
\end{array}\right]=\left[\begin{array}{c}
\phi_{m 0} \\
\phi_{y 0}
\end{array}\right]+\left[\begin{array}{ll}
\phi_{m m}(L) & \phi_{m y}(L) \\
\phi_{y m}(L) & \phi_{y y}(L)
\end{array}\right]\left[\begin{array}{c}
Z_{m t} \\
Z_{y t}
\end{array}\right]+\left[\begin{array}{c}
\varepsilon_{m t} \\
\varepsilon_{y t}
\end{array}\right]
$$

Where $\phi_{i j}(L)=\sum_{k=1}^{p} \phi_{i j, k} L^{k}$ and $\mathrm{i}, \mathrm{j}=\mathrm{m}, \mathrm{y}$. L is lag operator and written as $L^{k} z_{i t}=z_{i t-k}$ and $\mathrm{i}=$ $\mathrm{m}, \mathrm{y}$. To test $\mathrm{H}_{0}$ hypothesis of real GDP does not Granger cause export, we should impose zero restrictions on $\varphi_{m y, i}=0$ for " $i=1,2, \ldots, p^{\prime \prime}$ jointly. It means real GDP does not contain predictive content (no causality) for export under the null hypothesis;

$$
H_{0}^{M}: \phi_{m y, 1}=\phi_{m y, 2}=\ldots \ldots=\phi_{m y, p}=0
$$

In similar way, the null hypothesis that export does not Granger cause real GDP can be tested by using same restriction on $\varphi_{m y, i}=0$ for $i=1,2, \ldots, p$. In this situation jointly zero restrictions under the null hypothesis can be write as; 


$$
H_{0}^{Y}: \phi_{y m, 1}=\phi_{y m, 2}=\ldots . .=\phi_{y m, p}=0
$$

At this point ELG and GLE hypotheses are related to the null hypothesis of Granger causality (10) and (11) in two ways. First one is requires rejection of $H_{0}^{Y}$ but not of $H_{0}^{M}$. This is narrow definition because it handle the subject in unidirectional. This definition explains the causality relationship in favour of the ELG hypothesis. But if the null hypothesis specified under $H_{0}^{M}$ is rejected, but not of $H_{0}^{M}$, it means supportive of the GLE hypothesis. Second one is present more comprehensive definition of causality relationship. Under this frame if $H_{0}^{Y}$ in is rejected or both $H_{0}^{Y}$ and $H_{0}^{M}$ are rejected, it will provide evidence in favour of the ELG hypothesis. Likewise, the rejection of $H_{0}^{M}$ or the rejection of both $H_{0}^{Y}$ and $H_{0}^{M}$ makes evidence in favour of the GLE hypothesis. As it is understood, narrow definition allows bidirectional causality but broader definition supports unidirectional causality. At that, these definitions provide us useful implications in the case of foreign trade policy. For example if there is positive unidirectional causality that goes exports to real GDP, exports incentives and other supportive decisions will be affect economic growth positively. When we talk about bidirectional causality, in addition to export promoting policies, increase in economic growth will also boost exports volume alternately. On the other hand, if a unidirectional causality exists only from real GDP to exports, exports promoting policies will be ineffective and in this case policymakers should emphasis on increase in output growth. (Helpman, 1984; Grossman \& Helpman, 1989; Rivera-Batiz \& Romer, 1991; Baldwin \& Forslid, 2000).

\subsection{Parameter Stability Test}

The most important point in our methodology is structural change. Standard Granger test assumes parameters constancy about VAR model over whole sample period but in business world, economic variables have exposed too many factors which are influencing dynamics of macroeconomic basis of a country. In this dynamic world, significance and influence of any factor can be increase or decrease over time period (Tarasayev et al., 2017). So parameters stability assumption is not a realistic approach. Because of changes in structural environment, linearity assumption may be violated. Under structural change, parameters in VAR models shift in time and this change gives rise to unstable causal relationship between exports and real GDP. Therefore assumptions of parameter stability and a single causal relationship across the full time period under causality tests may be misleading (Zeileis et al., 2005). This is important problem that researcher has to tackle. So it is required to test for constancy both for short-run and long-run period. For this purpose, we employed Sup-F, Mean-F and Exp-F tests developed by Andrews (1993) and Andrews and Ploberger (1994) and $L_{c}$ test of Nyblom (1989) to run VAR model properly under temporal stability.

\subsection{Sub-Sample Rolling Window Granger Causality Test}

Structural changes would be considered in time series analysis in various ways such as dummy variables or sample splitting. But it is mentioned before, these methods contain pre-test bias. Accordingly, to overcome parameter instability and to avoid pre-test bias, we employed rolling window bootstrap estimation method. The key feature of this method is divided the full sample into fixed-size subsamples which are named as rolling window. This technique is conducted on rolling window sequentially from the beginning to the end of the sample. Specifically full sample is converted to a sequence of T-/ sub-samples, that means; $\mathrm{t}=\tau-I+1, \tau-I, \ldots . . \tau$ and $\tau=I+I+1 \ldots \ldots . \mathrm{T}$ where $I$ is the size of rolling window. Than instead of estimating a single causality test for full sample classically, the residual based modified-LR causality test is applied to each sub-sample. By calculating the bootstrap p-values of observed LR-statistic we can identify possible structural changes in the causal links. In our study we estimate the VAR model in Eq. (9) for a time span of 15 quarters rolling through $t=\tau-14, \tau-13, \ldots . \tau$, where $\tau=15, \ldots, T$. Hence we reported results with window size of 15 observations. We calculate the bootstrap $p$-values of the null hypothesis; GDP does not Granger cause export (all $\varphi_{\text {Export,GDP, } i}=0$ for $i=1,2, . ., p$ ) and the export does not Granger cause GDP (all $\varphi_{G D P, \text { export, } i}=0$ for $i=1,2, \ldots$, p), using the RB bootstrap method (Horowitz, 1994). 
The magnitude of the effect of exports on real GDP is derived from the $N_{b}^{-1} \sum_{k=1}^{p} \widehat{\emptyset}_{y m, k}^{*}$ formula. In this equation ' $N_{b}$ ' represents number of bootstrap repetitions. Likewise impact of real GDP on export is derived from; $N_{b}^{-1} \sum_{k=1}^{p} \widehat{\emptyset}_{m y, k}^{*}$ formula. Both $\widehat{\emptyset}_{m y, k}^{*}$ and $\widehat{\emptyset}_{y m, k}^{*}$ are bootstrap estimates based on VAR models in equation (9). We also computed 90-percent confidence intervals where the lower and upper limits equal 5 th. and 95 th. quantiles of each of the $\widehat{\emptyset}_{m y, k}^{*}$ and $\widehat{\emptyset}_{y m, k}^{*}$ respectively (Balcılar et al., 2010).

Before conducting the test we have to highlight some constraints. There is inverse relationship between representativeness of the model and accuracy of the parameters. In other words there is trade-off between window size I and the number of rolling window estimates. Accuracy of this technique is depend on increase in each regression and the window size $l$. Firstly it maximizes number of rolling regressions because small window size such as one by one exhibit more detailed transition. On the other hand large window size may improve the robustness of estimates but may reduce the representativeness. However small window size decrease heterogeneity and advance the representativeness of parameters but it cause increase in standard errors of estimates and thus may weaken parameter accuracy. So it would be better to set windows size according to balance between representability and accuracy.

There is no consensus on window size. In the literature when deciding the suitable window size, researcher has been taken into account two conflicting view. First one is degree of freedom and second one is structural changes. More clearly under structural changes, windowed sample claims for a smaller window size. But degree of freedom that relates to the precision of parameter estimates requires for a larger window size (Yang \& Wu, 2015). Therefore we pay attention to balance between representativeness and accuracy. Within this scope, window size of 15 quarters is selected in this paper.

\section{Empirical Results}

\subsection{Descriptive Statistics}

Before conducting standard granger test, it would be useful to demonstrate statistical properties of the time series. Time series usually follow a random process so it is important to check stationarity of the series prior to estimation. Firstly it would be useful to see graphics of variables in levels to check unit root visually. As it seen from figure 1 all series have deterministic upward trend. It means series in level are not stable. Secondly we present common statistics of data set to describe basic features of variables in Table 1. Firstly skewness is the third moment of normal probability distribution and it refers to measurement of symmetry. It's value can be either positive or negative (Doane \& Seward, 2011). For our dataset, all variables are positively skewed.

Figure 1. Time Series Plots of the Variables (In Billions of USD)
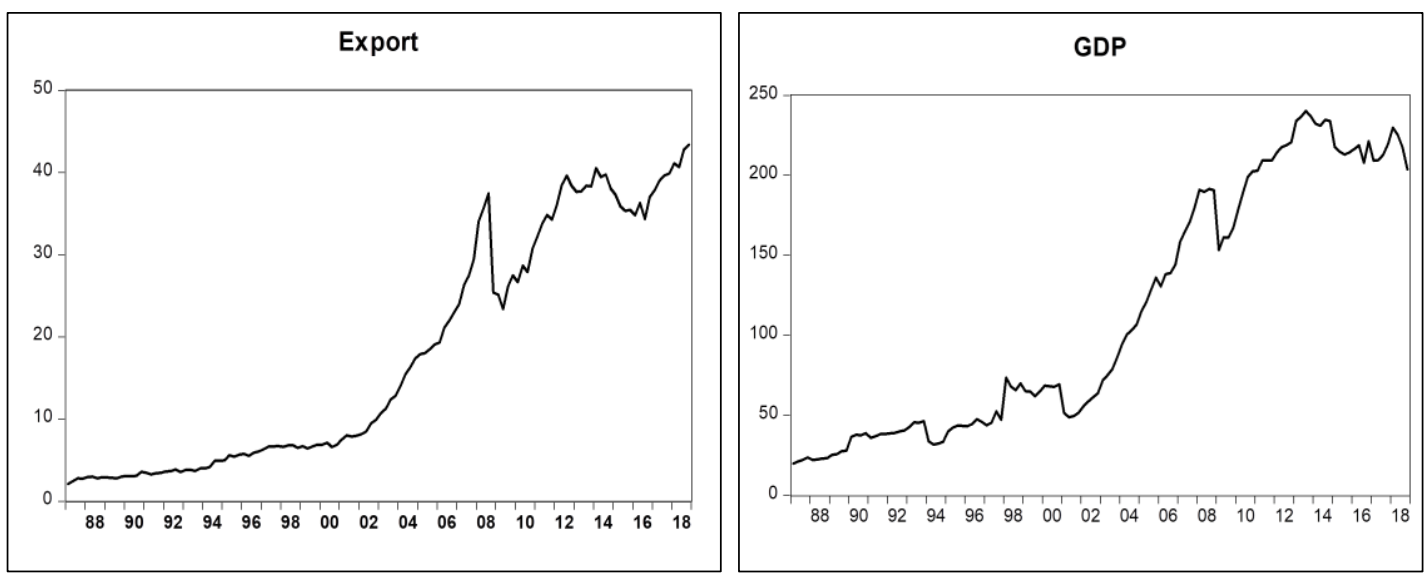
Table 2. Descriptive Statistics of Data Set

\begin{tabular}{|c|c|c|}
\hline & Export & GDP \\
\cline { 2 - 3 } Mean & 17663127 & 113000000000 \\
Median & 10313976 & 72700000000 \\
Maximum & 43391299 & 240000000000 \\
Minimum & 2108029 & 19800000000 \\
Std. Dev. & 14269242 & 77600000000 \\
Skewness & 0.45294 & 0.35768 \\
Kurtosis & 1.53938 & 1.44289 \\
Jarque-Bera & 15.75487 & 15.66047 \\
(Probability) & 0.00038 & 0.00040 \\
Sum & $2.26 \mathrm{E}+09$ & $1.45 \mathrm{E}+13$ \\
Sum Sq. Dev. & $2.59 \mathrm{E}+16$ & $7.65 \mathrm{E}+23$ \\
Observations & 128 & 128 \\
\hline
\end{tabular}

Secondly, kurtosis describes the shape of a random variable's probability distribution and can be formally defined as the standardized fourth population ( $\beta$ ) moment about the mean (De Carlo, 1997). Table 1 , Kurtosis values of all variables are less than 3 , and this indicates that distribution has lighter tails and a flatter peak than the normal distribution. Therefore, from those kurtosis and skewness values it could be said that the dataset is normally distributed. But to be more precise, Jargue-Bera test statistic should be evaluated. According to Jarque-Bera test statistic, the null hypothesis of error term is rejected $(0.00038$ and $0.0004<0.01$ ) in terms of their probability means that series are normally distributed.

\subsection{Unit Root Test and Cointegration}

Following descriptive statistics, the presence of a nonstationarity is determined by unit root tests like Dickey and Fuller 1979 (ADF), Phillips and Perron 1988 (PP), and Kwiatkowski et al. 1992 (KPSS). Under the null hypothesis of "non-stationarity", test results are as follows;

Table 3. Unit Root Tests

\begin{tabular}{|l|ccc|ccc|}
\hline \multirow{2}{*}{ Variable } & \multicolumn{3}{|c|}{ Level } & \multicolumn{3}{c|}{ First Difference } \\
\cline { 2 - 7 } & ADF & PP & KPSS & ADF & PP & KPSS \\
\hline Export & $-1.231(0.65)$ & $-1.206(0.67)$ & 1.359 & $-11.291(0.00)$ & $-11.288(0.00)$ & $0.155^{* * *}$ \\
GDP & $-1.568(0.49)$ & $-1.584(0.48)$ & 1.343 & $-11.322(0.00)$ & $-11.322(0.00)$ & $0.183^{* * *}$ \\
\hline
\end{tabular}

Notes: $H_{0}:$ Null hypothesis of unit root. The numbers in parenthesis indicates probability value.

(***',**, and * denotes statistical significance at the $\% 1, \% 5$, and $10 \%$ level. The lag order is determined by Schwarz Bayesian Criterion (SBC).

According to ADF, PP and KPSS tests, we fail to reject the null hypothesis at $\% 1$ level. Therefore its proved that series are I(1) processes. After unit root has been confirmed for our data we can determine longrun equilibrium relationship by using Johansen approach. In order to investigate cointegration, Johansen maximum likelihood method is used. In this frame we used Schwarz Information Criteria (SIC) to determined optimal lag order ( $p)$ in bivariate linear VAR model. According to SIC criteria optimal lag order is 2 . Table 4 show us diagnostic results. Robustness of VAR (2) model is proved by AR roots are less than 1, there is no heteroscadasticity and no auto correlation. After diagnostic tests Table 4 gives the results of the Johansen cointegration trace test statistics. 
Revisit Exports-Growth Nexus in Turkey

Table 4. Test for Stability Condition of VAR (2) Model

\begin{tabular}{|cc|ccc|ccc|}
\hline \multicolumn{2}{|c|}{ Inverse } & Roots of AR & \multicolumn{3}{|c|}{ Serial Correlation LM } & \multicolumn{2}{c|}{ Res. Heteroskedasdicity Test } \\
\hline Root & Modulus & Lags & LM-Stat & $\frac{\text { Prob }}{3}$ & \multicolumn{3}{c|}{ Joint test: } \\
0.994883 & 0.994883 & 1 & 3.43239 & 0.4882 & Chi-sq & $\frac{\text { df }}{\text { Prob. }}$ & $\underline{ }$ \\
0.803949 & 0.803949 & 2 & 5.008227 & 0.2865 & 35.52544 & 24 & 0.061 \\
0.092857 & 0.092857 & 3 & 2.137175 & 0.7105 & & & \\
-0.07322 & 0.073219 & 4 & 9.36718 & 0.0475 & & & \\
\hline
\end{tabular}

Table 5. Cointegration Test Based on Johansen Approach

\begin{tabular}{|c|c|c|c|c|c|}
\hline Model Type & Hyp. No. of CE(s) & Eigenvalue & Trace & Crit. Val. (0.05) & Prob. \\
\hline \multirow{2}{*}{ Model 2} & None & 0.1629 & 31.16 & 20.26 & 0.000 \\
\hline & At most 1 & 0.0671 & 8.75 & 9.16 & 0.058 \\
\hline \multirow{2}{*}{ Model 3} & None & 0.1166 & 16.34 & 15.49 & 0.037 \\
\hline & At most 1 & 0.0056 & 0.71 & 3.84 & 0.398 \\
\hline \multirow{2}{*}{ Model 4} & None & 0.1261 & 19.72 & 25.87 & 0.243 \\
\hline & At most 1 & 0.0214 & 2.73 & 12.71 & 0.906 \\
\hline \multicolumn{6}{|c|}{ Pantula Principle } \\
\hline Rank $r$ & $\frac{\text { Case } 2}{16\left(H_{0} \text { Reiect }\right.}$ & \multicolumn{2}{|c|}{$\frac{\text { Case } 3}{34 \text { ( } \mathrm{H}_{0} \text { Reject) }}$} & \multicolumn{2}{|l|}{$\frac{\text { Case } 4}{72\left(\mathrm{H}_{0} \mathrm{~A}\right.}$} \\
\hline At most 1 & 8.75 ( $\left.\mathrm{H}_{0} \mathrm{Accept}\right)$ & \multicolumn{2}{|c|}{0.71 ( $\mathrm{H}_{0}$ Accept) } & \multicolumn{2}{|c|}{2.73 ( $\mathrm{H}_{0}$ Accept) } \\
\hline
\end{tabular}

We determined existence of cointegration by following pantula principle. It involves testing sequentially a series of joint hypotheses. It's started with case 2 and co-integration rank of zero (none) flits to next case as long as if cointegration is rejected by critical values. This process continues until the preferred model is identified by the first time that the joint hypothesis is not rejected firstly. As it seen that the maximum eigenvalue statistics and the trace statistics results are less than the critical value; and therefore, the hypothesis of "no cointegration" cannot rejected.

\subsection{Granger Causality Test Results based on Full Sample}

Nextly we investigate the causal relationship between exports and real GDP for Turkish economy by using standard Granger noncausality test in the bivariate VAR framework. So we used residual based (RB) modified-LR tests, as suggested by Mantalos and Shukur (1998), Shukur and Mantalos (2000) and Hacker and Hatemi-J (2006). After finding no cointegration between variables, restrictions are tested by using a VAR ( $p$ ) model in difference variables. For this purpose we first determine the lag order of the VAR model by using the SIC. Accordingly VAR (2) model was selected for testing the model. The results of full sample residual based (RB) modified-LR statistic with its bootstrap p-values and also standard F-test based on the VAR(2) model is presented in Table 6.

Table 6. Full Sample Bootstrap Granger Causality Tests

\begin{tabular}{|l|cc|cc|}
\hline \multirow{2}{*}{} & \multicolumn{2}{|c|}{$\begin{array}{c}H_{0}: \text { Export does not } \\
\text { Granger cause GDP }\end{array}$} & \multicolumn{2}{|c|}{$\begin{array}{c}H_{0}: \text { GDP does not } \\
\end{array}$} \\
\cline { 2 - 5 } & Statistic & P-Value & Statistic & P-Value \\
\hline Standart VAR (2) F Test & 17.711 & 0.00 & 1.342 & 0.51 \\
Bootstrap LR Test & $6.21^{* *}$ & 0.04 & 0.936 & 0.62 \\
\hline
\end{tabular}

'**' represent significance at the $5 \%$ levels. In bootstrap $L R$ test, for "export does not granger cause GDP" hypothesis, bootstrap critical values are 12.53 (\%1), 7.09 (\%5) and 5.07 (\%10). For second hypothesis critical values are 14.87(\%1), 7.11(\%5) and $4.84(\% 10)$. 
Based on the standard granger test, the null hypotheses are rejected for "exports does not Granger cause real GDP" at \%1 level but accepted for "real GDP does not Granger cause exports". So this results indicating presence of full-sample uni-direction causal links that only run from exports to real GDP. Secondly full sample bootstrap LR statistic and its $p$-values are estimated. The results show that we reject the null hypothesis of 'exports does not Granger cause real GDP, but accept real GDP does not Granger cause exports. Thus we can conclude again that there is only one-way causality running from exports to real GDP.

\subsection{Empirical Results from Stability Test}

In this section we tested parameters stability which may cause shift in parameter values and the patterns of cointegration and causality linkage may change over time. Also the results of the Granger causality tests will be sensitive to lag order and sample period. Salman and Shukur (2004) indicted that when the assumption of parameter constancy is violated, due to structural changes or regime shifts, this test can provide misleading inference about the subjected relationship or resulted with biased inferences, inaccurate forecast and may affect the cointegration relationship. Therefore assumptions of parameter constancy and a single causal relationship across the whole sample period are not reliable in full-sample causality tests (Zeileis et al., 2005).

In the literature there are Sup-LR, Ave-LR, Exp-LR and $\mathrm{L}_{c}$ tests to check constancy of the parameters. On that account, we used these tests developed by Andrews (1993) and Andrews and Ploberger (1994) for temporal stability of parameters in the VAR model. Among them, Sup-LR statistics are used to tests parameter constancy against a onetime sharp shift in parameters for testing short-run parameter stability. On the other hand the Ave-LR and Exp-LR tests assume that parameters follow a martingale process. Thus if the regime shift is gradual, these are appropriate. In contrast to the $L_{c}$ test, these tests require trimming from the ends of the sample. Also we conducted the $L_{c}$ test of Nyblom (1989) and Hansen (1992) to investigate long run stability against the alternative hypothesis that the parameters follow a random walk process. According to these tests, if the long and short run parameters are stable, then the VAR model exhibits full structural stability.

Table 7. Parameter Stability Tests in VAR(2) Model.

\begin{tabular}{|c|c|c|c|c|c|c|}
\hline \multirow{2}{*}{ Test } & \multicolumn{2}{|c|}{ Real GDP Equation } & \multicolumn{2}{|c|}{ Export Equation } & \multicolumn{2}{|c|}{ VAR (2) System } \\
\hline & Statistics & P-Value & Statistics & P-Value & Statistics & P-Value \\
\hline Ave-LR & 21.20 & $0.04 * *$ & 35.77 & 0.99 & 11.05 & $0.01 * * *$ \\
\hline Exp-LR & 26.29 & $0.00 * * *$ & 55.22 & 0.99 & 2.11 & $0.04 * *$ \\
\hline Sup-LR & 58.89 & $0.00 * * *$ & 118.82 & $0.00 * * *$ & 1.85 & 0.13 \\
\hline Lc & 2.41 & $<0.01 * * *$ & 2.42 & $<0.01 * * *$ & $0.14^{b}$ & $0.02 * *$ \\
\hline
\end{tabular}

stability test for all parameters in the $\operatorname{VAR}(2)$ jointly.

According to results in Table 7, GDP equation has not stable parameters. It means their data evolve gradually with time. But according to Ave-LR and Exp-LR statistics in exports equation, there is evidence of parameter stability. On the other hand, the Sup-LR statistic in exports equation shows evidence for parameter instability. Secondly it's also proved that long-run parameters of VAR(2) model does not constant according to Ave-LR and Exp-LR results. Lastly according to $L_{c}$ test it can be reject the null hypothesis of constancy for both the exports and real GDP equations at the $1 \%$ significance level and also for VAR(2) as a system means that it does not have constant long-run parameters. So statistical inference based on this equation is may be misleading. Because of no cointegration relationship between exports and real GDP, one can be suspected that these results might be based on structural change, therefore, we conducted same test for the long-run relationship. Specifically, Sup-LR, Ave-LR and Exp-LR tests, as well as the $L_{c}$ test are used to check parameters stability in the long run. 
Table 8. Parameter Stability Tests of the Long-Run Relationship

\begin{tabular}{|c|c|c|c|c|}
\hline & Sup-LR & Ave-LR & Exp-LR & Lc \\
\hline Ingdp $=\alpha+b^{*}$ Inexport & 19.71 & 2.94 & 5.70 & 2.41 \\
\hline $\mathrm{p}$-Value & $0.00^{* * *}$ & $0.00^{* * *}$ & $0.00^{* * *}$ & $<0.01^{* * *}$ \\
\hline
\end{tabular}

According to Table 7, $p$ values show that the $L_{c}$ test statistics reject the null hypothesis of cointegration at $1 \%$ significance level. Also in the same table we also reject the null hypothesis of parameters according to the Sup-LR, Ave-LR, and Exp-LR test constancy at $1 \%$ significance level.

\subsection{Sub-Sample Rolling Window Granger Causality Test}

After determining parameter stabilities of the series, we can perform rolling-window test. For this reason we estimated each of the VAR models by using rolling window regression technique. Accordingly subsample of fixed length is changed at the beginning of the sample and moved sequentially to the end. In every window VAR model is estimated and performed the bootstrap causality test. By means that we consider the system that may be evolving over time and thus takes structural changes into account across different sequence of sub-samples for a 15 quarter fixed window.

Figure 2. Estimation Results from Export to Real GDP

Panel: A

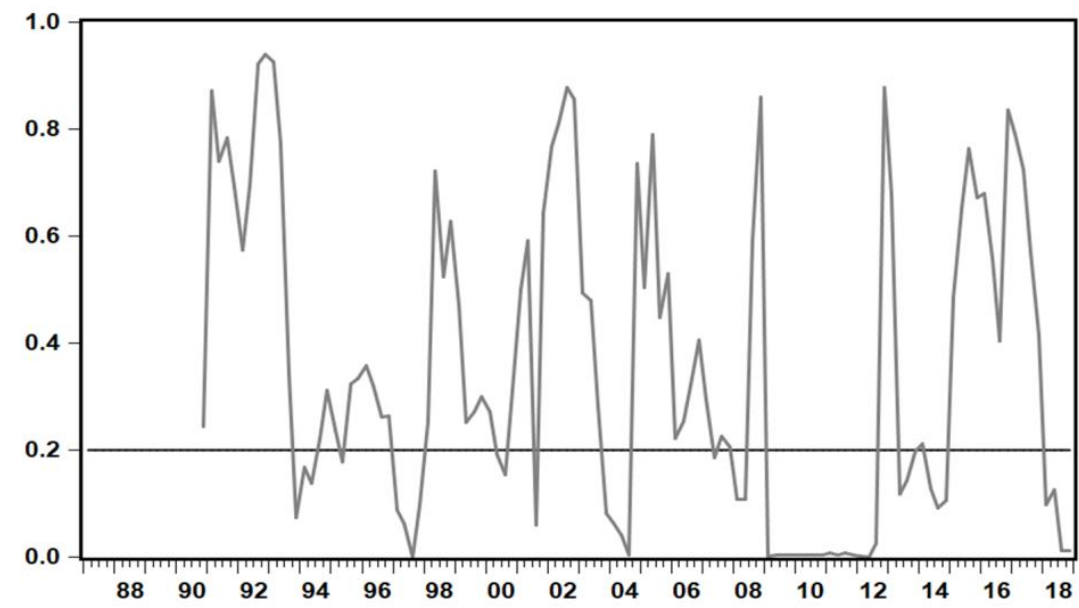

Panel: $B$

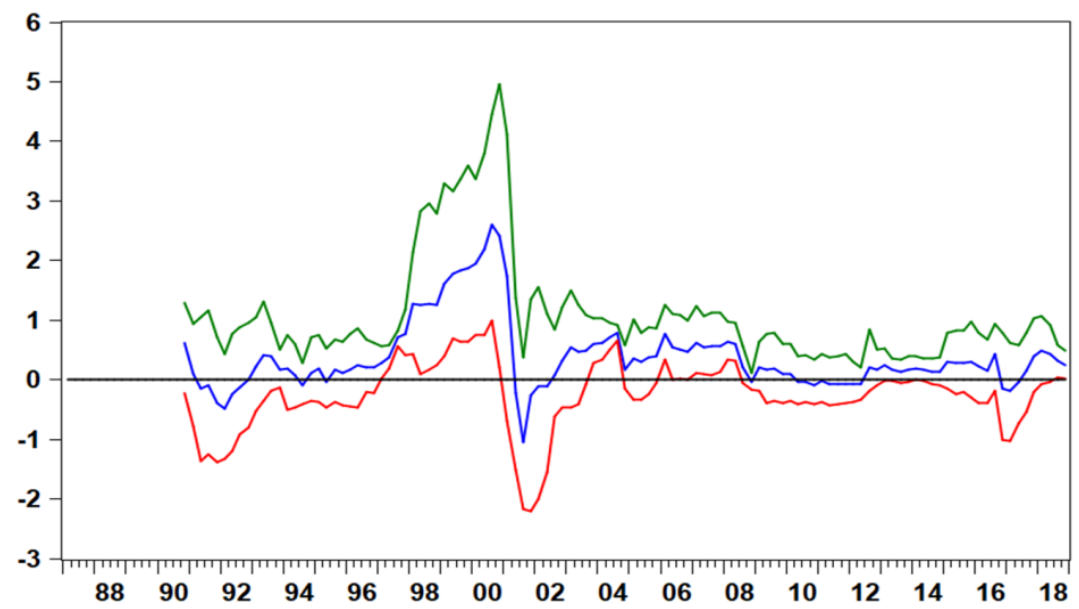


Figure 2 in panel A exhibits the p-values of the rolling test statistics under the null hypothesis of "exports does not Granger-cause real GDP". Horizontal axes show the final observation in each of the 128quarter rolling windows. Because of small sample size we will evaluate the tests at $20 \%$ significance level to maintain against the low test power (Balcılar \& Özdemir, 2013). Secondly Panel B shows the bootstrap estimates. From the beginning of the full sample $15 \%$ was trimmed from both ends and calculated these tests for the fraction of the sample in $[0.15,0.85]$ for the period of $1987 Q 1$ to $2018 Q 4$. Both figure in panel B, blue line shows sum of the rolling window coefficients, green line shows upper bound and the red line shows for lower bounds.

According to figure, the null hypothesis is not rejected at the $20 \%$ significance level during most of the sample. But exports have predictive power on real GDP for 1993Q/1994Q2, 1997Q1/1997Q4, 2000Q2/2000Q3, 2001Q3, 2003Q4/2004Q3, 2007Q4/2008Q2, 2009Q1/2012Q4, 2013Q2/2013Q4 and 2018Q1/2018Q4 periods. It means export has a significantly impact on real GDP for these sub periods. After last global financial downturn, this impact had been visible especially between 2009Q1-2012Q4 relatively long sup periods. In panel B, we exhibit the bootstrap estimates of sum of the rolling coefficients measuring impact (negative or positive) of export on real GDP. In these sub periods the sign of the impact of export is positive and statistically significant for 1993Q3/1994Q2, 1997Q1/1997Q4, 2003Q4/2004Q3, 2007Q4/2008Q2, 2013Q2/2013Q4. 2018Q1/2018Q4 periods. On the other hand the sign is negative only for 2001Q3. It means exports series have a predictive content (causality runs from exports to real GDP) in positive direction for these periods. Also these results are similar to the results from full sample causality test in table 6. It suggests that exports are performed as boosting economic growth in compliance with ELG hypothesis which is parallel to Grabowski et al. (1990) and Sharma et al. (1991).

Figure 3. Estimation results from Real GDP to Export

Panel: $A$

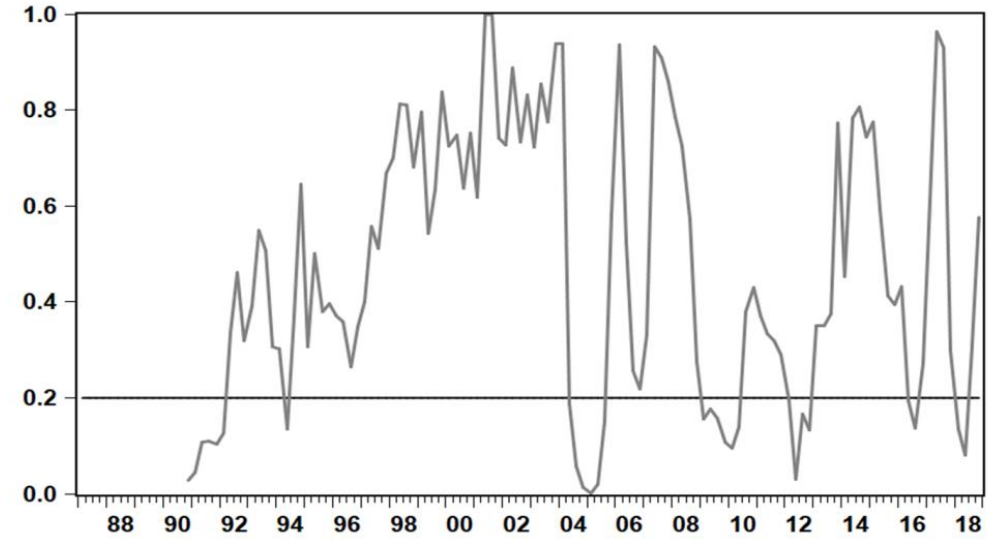

Panel: $B$

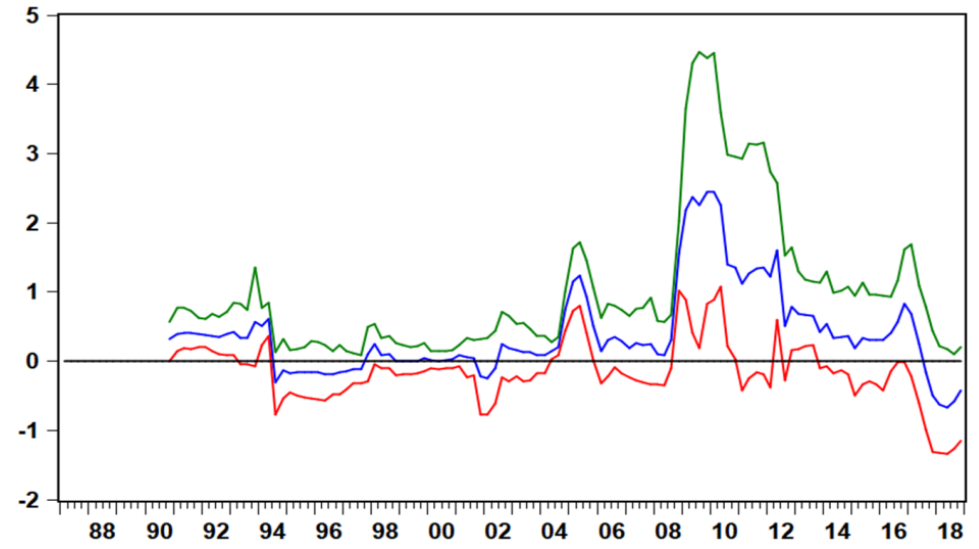


Figure 3 in panel A, shows change in p-values of the rolling test statistics of real GDP does not Granger cause export and panel $B$ shows the bootstrap estimates of sum of the rolling coefficients. Based on the findings from panel $A$, the null hypothesis is rejected for 1990Q4/1991Q2, 1994Q2/1994Q3, 2004Q2/2005Q4, 2009Q1/2010Q2, 2012Q1/2012Q4 and 2018Q1/20182Q3. Comparing with the null hypothesis of real GDP does not Granger cause export in table 6 , we can say that there are changes in causal links over the sample period. As it seen from panel A in figure 3, there are five sub periods during which real GDP seems to have predictive content on exports. Secondly in panel $B$, the impact of real GDP on exports is positive and statistically significant in 1990Q4/1991Q2, 2004Q2/2005Q4, 2009Q1/2010Q2 and 2012Q1/2012Q4.

The results from the rolling window causality tests revealed some main findings. Firstly it's not easy to say Granger causality both for ELG and GLE hypothesis are supported clearly. On the other hand there are some sub-periods where provide evidence for bidirectional causality. Granger causality tests are relatively robust to period changes and time-varying especially for the causality link about export to real GDP. In other words, $p$-values of the null hypothesis of exports does not granger cause real GDP is rejected longer time period than for the other direction.

Panel B's in both figure revealed that there is three each sharp change in the value of $p$ values. Firstly under the null hypothesis of "exports does not granger cause real GDP", fall in p-values is much larger and explicit during 2001 crisis but under the null hypothesis of "real GDP does not cause export", fall in $p$ values is more apparent during 2008 global financial crisis. During these periods GDP growth and exports prices are highly volatile and predictive content for GDP on export became apparent. When we talk about magnitude and the direction of causality between the series, although exports have a more predictive content (positive direction) on real GDP than real GDP on exports, bootstrap full sample tests imply a bi-directional causality link. As it stated before, findings of significant number of studies on this subject can be mixed and often contradictory. For this paper, as it seen from all figures, findings show that there is a positive two way causality from mid-1990s to end of 2018 at intervals. According to these results, exports performed as economic growth-boosting function. However at the level of recovery growth stage, real GDP contributing export growth as well as the increasing level of investment (Awokuse, 2006) especially after crisis (1994, 2001 and 2008) period.

\section{Conclusion}

This article aims to investigate the causal relationship between exports and real GDP over the 1987Q1- 2018Q4 periods for Turkish economy. Different from previous papers, we employed full sample and rolling window Granger non-causality tests. Also in order to specify the size and the direction of the relationship, we estimated bootstrap of sum of the rolling coefficients. According to results, there is a positive two way (it suggests feedback hypothesis) granger causality between series. Second, GDP have predictive power on exports during only post crisis $(1994,2001$ and 2008) periods, but exports series have predictive power on GDP from the early 1990s to 2018 at determined intervals. Besides predictive power of export series on real GDP has more significant manner than the other direction. Also periods of causal links are associated with various significant real economic changes e.g. the structural reforms and restructuring programs following the 1994 crisis, 2001 currency crisis and 2008 global financial crisis.

The 1994 was characterized by improper policies such as pursuing fiscally damaging populist economic programs, accelerating capital inflow, uncontrolled trade and financial liberalization, large and growing fiscal (high public debt) and external imbalances imbalance (current account deficit) following the capital account liberalization in 1989, real exchange rate appreciation, some policy mistakes about monetary policies. These imbalances were resulted with 1994 crisis. At first step the government responded to crisis by applying IMF backed stabilization program on April 5, 1994 but following government neglected and delayed implementation of the structural measures of stabilization program. Secondly 2001 crisis were mainly characterized by high interest rates and chronic inflation, severe contraction in domestic demand and currency devaluation. After 2001 crisis fundamental reforms have been undertaken and strict fiscal discipline has been implemented and imposed stringent regulations of the financial sector to combat chronic reckless 
pork barrel spending, incomes policies and privatization program implemented, exchange rates are floated, budget deficit is stabilized, inflation started to decreased, the state-owned and private banks were restructured while also legalizing Central Bank independence. Thirdly after 2008 global crisis, several economic stimulus packages were put into effect e.g. budget deficit raised, fiscal and monetary policies loosened, tax rates (special consumption and value added) are decreased and tax for incomes earned abroad are exempted, investment and capital inflows (asset peace low) are promoted, liquidity and capital needs of banking sector is met and social security premiums are decreased to rise employment rate.

As it understood, because of different basic dynamics of 1994, 2001 and 2008 crisis, different measures were undertaken to ease negative effect of crisis. But commonly, promoting export are always one of the main policies implemented by the Turkish governments with the hope of stimulating economic growth. It's crucial role for Turkish economy derives from its close relation with economic growth and current account deficit. It usually considered as a way for riding out the crisis and in turn boost economic growth. Hence steady and increasing export pattern is one of the most important components of sustainable economic growth. Current account deficit and its finance are one of the most debated macroeconomic issues after 1980s periods. Outward oriented program of 1980 changed Turkey its focus from an import substitution strategy to an export-oriented one. However this radical change makes Turkish economy is always suffer from high current account deficit and hot money flow. Turkey's large external financing needs poses a threat to macro-financial stability and sudden loss of investor confidence, changes in global risk sentiment makes the Turkish currency vulnerable to exchange rate fluctuations and fluctuating cycles in economic activity. In addition, low saving rates, dependence of domestic industry and energy sector (Turkish economy is highly dependent on energy imports due to lack of domestic sources) on imported inputs deepened this problem. So need for increasing exports volume is vital for highly debted Turkish economy. Increasing export is sustainable way of successful macroeconomic performance.

\section{References}

Aktaş, C. (2009). Causality analysis of import, export and economic growth of Turkey. Kocaeli University Journal of Social Science Institute, 18(2), $35-47$.

Andrews, D. W. K. (1993). Tests for parameter instability and structural change with unknown change point. Econometrica, 61(4), 821-856.

Andrews, D. W. K., \& Ploberger, W. (1994). Optimal tests when a nuisance parameter is present only under the alternative. Econometrica, 62, 1383-1414.

Awokuse, T. O. (2006). Export-led growth and the Japanese economy: Evidence from VAR and directed acyclic graphs. Applied Economics, 38, 593-602.

Awokuse, T. O., \& Christopoulos, D. K. (2009). Nonlinear dynamics and the exports-output growth nexus. Econ Model, 26, 184-190.

Ay, A., \& Gerçeker, M. (2013). Export, import and economic growth causalities: Turkish Case (1998-2010). Journal of Finance, Politics and Economic Analysis, 50(578), 17-30

Başarır, Ç., \& Erçakar, M. E. (2016). An analysis of the relationship between crude oil prices, current account deficit and exchange rate. International Journal of Economics and Finance, 8(11), 48-59.

Balassa, B. (1978). Exports and economic growth: Further evidence. Journal of Development Economics, 5(2), $181-189$.

Balcılar, M., Özdemir, Z. A., \& Arslantürk, Y. (2010). Economic growth and energy consumption causal nexus viewed through a bootstrap rolling window. Energy Economics, 32(6), 1398-1410.

Balcılar, M., \& Özdemir, A. Z. (2013). The export-output growth nexus in Japan: A bootstrap rolling window approach. Empirical Economics, 44, 639-660.

Baldwin, R. E., \& Forslid, R. (2000). Trade liberalisation and endogenous growth: A q-theory approach. Journal of International Economics, 50, 497-517.

Bilgin, C., \& Şahbaz, A. (2009). Causality relations between growth and export in Turkey. Gaziantep University Journal of Social Science Institute, 8(1), 177-198. 
De Carlo, L. T. (1997). On the meaning and use of kurtosis, psychological method. American Psychological Association, 2(3), 292-307.

Dickey, D. A., \& Fuller, W. A. (1979). Distribution of the estimators for autoregressive time series with a unit root. Journal of American Statistical Association, 74(366), 427-431.

Dickey, D. A., \& Fuller, W. A. (1981). Likelihood ratio statistics for autoregressive time series with a unit root. Econometrica, 49(4), 1057-72.

Doane, P. D., \& Seward, E. L. (2011). Measuring skewness: A forgotten statistic? Journal of Statistics Education, 19(2), DOI: 10.1080/10691898.2011.11889611.

Dolado, J. J., \& Lütkepohl, H. (1996). Making Wald test s work for cointegrated VAR systems. Econometrics Reviews, 15, 369-386.

Dolado, J. J., Gonzalo, J., \& Marmol, F. (1999). Cointegration. In B. H. Baltagi (Ed.), A companion to theoretical econometrics, Malden: Blackwell.

Efron, B. (1979). Bootstrap methods: Another look at the jackknife. Annals of Statistics, (7) 1-26.

Engle, R. F., \& Granger, C. W. J. (1987). Co-integration and error correction: Representation, estimation, and testing. Econometrica, 55(2), 251-276.

Engle, R. F., \& Yoo, B. S. (1987). Forecasting and testing in cointegrated system. Journal of Econometrics, 35(1), $143-159$.

Erdoğan, S. (2006). Relationship between structural change in export and economic growth: Cointegration and causality analyses. Selçuk University Karaman Faculty of Economics and Administrative Sciences, 9(10), 30-39.

Felipe, J. (2003). Is export-led growth passed? Implications for developing Asia. ERD Working Paper, No. 48.

Giles, J. A., \& Williams, C. L. (2000). Export-led growth: A survey of the empirical literature and some non-causality results. Journal of International Trade \& Econ Development, 9(3), 261-337.

Grabowski, R., Sharma, S. C., \& Dhakal, D. (1990). Exports and Japanese economic development. Economic Letter, 32, 127-132.

Granger, C. W. J. (1969). Investigating causal relations by econometric models and cross-spectral models. Econometrica, $37(3), 424-438$.

Grossman, G. M., \& Helpman, E. (1991). Innovation and growth in the global economy. Cambridge: MIT Press.

Grossman, G. M., \& Helpman, E. (1989). Product development and international trade. Journal of Political Economy, 97, 1261-1283.

Hacker, R. S., \& Hatemi-J., A. (2006). Tests for causality between integrated variables using asymptotic and bootstrap distributions: Theory and application. Applied Economics, 38(13), 1489-1500.

Hatemi-J., A. (2002) Export performance and economic growth nexus in Japan: A bootstrap approach. Japan World Economy, 14, 25-33.

Hansen, H., \& Juselius, K. (1998). Cats in rats: Co-integration analysis of time series. Journal of Applied Econometrics, 13, 321-330.

Helpman, E., \& Krugman, P. (1985). Market structure and foreign trade. Cambridge: MIT Press.

Helpman, E. (1984). A simple theory of international trade with multinational corporations. Journal of Political Economy, 92, 451-471.

Hjalmarsson, E., \& Österholm, P. (2007). Testing for cointegration using the Johansen methodology when variables are near-integrated. IMF Working Paper, WP/07/141.

Horowitz, J. L. (1994). Bootstrap-based critical values for the information matrix test. Journal of Econometrics, 61, 395411.

Hultman, C. W. (1967). Exports and economic growth: A survey. Land Economics, 43(2), 148-157.

Küçükksoy, İ., Çifçi, ì., \& Özbek, R. İ. (2015). Export-led growth hypothesis: Turkey application. Çankırı Karatekin Univ. Jour. of Faculty of Economics and Administrative Sciences, 5(2), 691-720.

Krueger, A. (1980). Trade policy as an input to development. American Economic Review, 70, 188-292.

Korkmaz, S. (2014). Causality relationship between export and economic growth in Turkish economy. Business and Economics Research Journal, 5(4), 119-128.

Kwiatkowski, D., Phillips, P. C. B., Schmidt, P., \& Shin, Y. (1992). Testing the null hypothesis of stationarity against the alternative of a unit root. Journal of Econometrics, 54, 159-178. 
Mantalos, P., \& Shukur, G. (1998). Size and power of the error correction model cointegration test: A bootstrap approach. Oxford Bulletin of Economics and Statistics, 60, 249-255.

Mantalos, P. (2000). A graphical investigation of the size and power of the granger causality tests in integrated-cointeg. VAR systems. Studies in Non-linear Dynamics and Econometrics, 4, 17-33.

Marin, D. (1992). Is the export-led growth hypothesis valid for industrialized countries? Review of Economics and Statistic, 74, 678-688.

Nyblom, J. (1989). Testing for the constancy of parameters over time. Journal of the American Statistical Association, $84,223-230$.

Oskooee, M. B., \& Economidou, C. (2009). Export led growth vs. growth led exports: Ldc's experience. The Journal of Developing Areas, 42(2), 179-212.

Özcan, B., \& Özçelebi, O. (2013). Is export-led growth hypothesis applicable to Turkey? Celal Bayar University The Journal of Faculty of Economics and Administrative Sciences, 20(1), 1-14.

Özer, M., \& Erdogan, L. (2006). Time series analysis of the relationship between export, import and economic growth in Turkey. Gazi University Economic Approach, 17(60-61), 93-110.

Özkaplan, D. (2011). Turkish credit default swap and relationship with financial indicators. İstanbul Bilgi University Social Science Institute, Master Thesis, Banking and Finance Program.

Pack, H. (1988). Industrialization and trade, handbook of development economics. Handbook of Development Economics, Vol. 1, chapter 9, pp. 333-380.

Park, J. P., \& Phillips, P. C. B. (1989). Statistical inference in regression with integrated process: Part 2. Economic Theory, 5, 95-131.

Pesaran, M. H., \& Timmermann, A. (2005). Small sample properties of forecasts from autoregressive models under structural breaks. Journal of Econometrics, 129, 183-217

Phillips, P. C. B., \& Perron, P. (1988). Testing for unit roots in time series regression. Biometrika, 75, 335-346.

Rivera-Batiz, L., \& Romer, P. (1991). Economic integration and endogenous growth. Quarterly Journal of Economics, 106, 531-555.

Saatçioğlu, C., \& Karaca, O. (2004). Causality relationship between exports and growth in Turkey: Effect of transformation in 1980. İstanbul University Graduate School of Business Journal of Management, 15(49), 30-40.

Sağlam, Y., \& Egeli, H. A. (2016). Export-led growth hypothesis: Turkish case. Dokuz Eylül University The Journal of Institute of Social Sciences, 17(4), 517-530.

Salman, A. K., \& Shukur, G., (2004). Testing for Granger causality between industrial output and CPI in the presence of regime shift: Swedish data. Journal of Economic Studies, 31(October), 492-499.

Sharma, S. C., Norris, N. M., \& Chung, D. W. (1991). Exports and economic growth in industrialized countries. Applied Economics, 23, 697-707.

Shukur, G., \& Mantalos, P., (1997a). Size and power of the RESET test as applied to systems of equations: A bootstrap approach. Department of Statistics Working Paper, University of Lund, Sweden.

Shukur, G., \& Mantalos, P. (1997b). Tests for Granger causality in integrated-cointegrated VAR systems. Department of Statistics Working Paper, University of Lund. Sweden.

Sims, C. A., Stock, J. H., \& Watson, M. W. (1990). Inference in linear time series with some unit roots. Econometrica, $58(1), 113-144$.

Takım, A. (2010). The relationship between GDP and exports in Turkey: Granger causality test. Atatürk University Journal of Social Sciences, 14(2), 315-330.

Tarasyev, A. M., Usova, A. A., \& Turygina, V. F. (2017). Structural changes in economic growth models. IFAC Papers OnLine, 50(1), 4875-4880.

Taştan, H. (2010). Spectral analysis of causality among exports, imports and economic growth in Turkey. Journal of Economic Sciences, 2(1), 87-98.

Temiz, D., \& Gökmen, A. (2010). An analysis of the export and economic growth in Turkey over the period of 1950-2009. International Journal of Econ and Administrative Studies, 3(5), 123-142.

Toda, H. Y., \& Phillips, P. C. B. (1993). Vector auto regressions and causality. Econometrica, 61, 1367-1393.

Toda, H. Y., \& Yamamoto, T. (1995). Statistical inference in vector auto regressions with possibly integrated processes. Journal of Econometrics, 66, 225-250. 
Yang, M., H., \& Wu, C., S. (2008). Revisit export and GDP nexus in China and Taiwan: A rolling window Granger causality test. Theoretical and Applied Economics, 22(3-604), 75-92.

Yıldırım, E. (2015). Is the export-led growth an illusion? Evidences from symmetric and asymmetric causality tests. Journal of International Economics and Administrative Studies, 15, 21-40.

Zeileis, A., Leisch, F., Hornik, K., \& Kleiber, C. (2005). Monitoring structural change in dynamic econometric models. Journal of Applied Econometrics, 20, 99-121.

Zivot, E., \& Wang, J. (2015). Modeling financial time series with s-plus. New York: Springer. 